\title{
Multiple Cerebral Infarctions Associated with Polycystic Ovaries and Ovarian Hyperstimulation Syndrome
}

\author{
Tae-Jin Song Seung-Yeob Lee Seung-Hun Oh Kyung-Yul Lee \\ Department of Neurology, Yonsei University College of Medicine, Yongdong Severance Hospital, Seoul, Korea
}

\section{Dear Sir,}

Ovarian hyperstimulation syndrome (OHSS) is a potentially lethal complication of ovulation induction $[1,2]$. OHSS can represent electrolyte imbalance, neurohormonal and hemodynamic changes, pulmonary manifestations, liver dysfunction, hypoglobulinemia, febrile morbidity and thromboembolic phenomena. Past studies have indicated that OHSS has a significant and consistent relationship with polycystic ovaries. When polycystic ovaries are present, OHSS can develop more frequently than in a normal female [3].

A thromboembolic phenomenon in OHSS is clinically important due to potential severe complications. Thromboembolism, combined with OHSS, occurs primarily in the venous system, but case reports of cerebral infarction in OHSS can also be found in the literature [4-6]. We report a case of massive and progressive cerebral infarction with OHSS and polycystic ovaries, occurring several days after in vitro fertilization and embryo transfer.

Case Report

A 31-year-old, left-handed woman was admitted with a chief complaint of left-sided motor weakness and motor aphasia. She had been diagnosed as having oligo-ovulation, infertility and polycystic ovaries at an infertility clinic 6 months previously. Her medical history was unremarkable: no history of hypertension, migraine or obesity, no family history of cardiovascular disease, no use of oral contraceptive or preventive medication for stroke. She had been nulligravida before this pregnancy. Ultrasonographic examination of the ovaries was performed by the infertility clinic and revealed multiple, bilateral follicles, $0.5-0.7 \mathrm{~cm}$ in size. Induction of ovulation began 28 days prior to focal neurological symptoms. The patient received oral clomiphene citrate (100 mg/day for 5 days) and injection of human menopausal gonadotropin (75 IU/day for 5 days). Two weeks later, 15 oocytes were retrieved and 6 embryos were transferred: 3 in the right endometrium, 3 in the left. Two days prior to admission at our hospital, ascites was observed during abdominal ultrasound, and a diagnosis of OHSS was made. At admission, blood pressure was $120 / 70 \mathrm{~mm}$ $\mathrm{Hg}$, with a regular pulse rate of $85 / \mathrm{min}$. On examination, the patient was slightly drowsy, was unable to speak fluently but able to comprehend, had a left visual field defect and severe left-sided motor weakness, including central-type facial palsy. The initial National Institutes of Health Stroke Scale (NIHSS) score was 18.

Laboratory tests demonstrated that the serum white blood cell count $(21,830 / \mu \mathrm{l})$ and levels of liver enzymes (aspartate aminotransferase $143 \mathrm{IU} / \mathrm{l}$; alanine aminotransferase 86 IU/l) were elevated, while serum albumin was decreased $(2.8 \mathrm{~g} / \mathrm{dl})$. Human chronic gonadotropin (hCG) was
$8.3 \mathrm{mIU} / \mathrm{ml}$ (2nd week after conception normal range, 0-400 $\mathrm{mIU} / \mathrm{ml}$ ); serum estradiol and progesterone levels increased up to $4,300 \mathrm{pg} / \mathrm{ml}$ (1st trimester normal range $100-5,600 \mathrm{pg} / \mathrm{ml}$ ) and $60.0 \mathrm{ng} / \mathrm{ml}$ (1st trimester normal range $11.2-90.0 \mathrm{ng} /$ $\mathrm{ml})$, respectively. Blood urea nitrogen, serum creatinine, prothrombin time, activated partial thromboplastin time, homocysteine and protein $\mathrm{C}$ were within normal limits. Anticardiolipin antibody, lupus anticoagulant and activated protein $\mathrm{C}$ resistance were negative. Protein $\mathrm{S}$ and antithrombin III were initially reduced during anticoagulation but normalized prior to the follow-up examination. Chest and abdominal CT demonstrated a pleural effusion in the right lung fields, ascites and multiple enlarged follicles in both ovaries (fig. 1). Ultrasonographic examination revealed bilateral enlarged ovaries (right $7.99 \mathrm{~cm} \times 7.94 \mathrm{~cm}$, left $9.95 \mathrm{~cm} \times 8.76 \mathrm{~cm})$ and follicles. MRI of the brain revealed an acute ischemic lesion on diffusion-weighted and $\mathrm{T}_{2}$-weighted imaging in the right middle cerebral artery territory, but no occlusions of the major intracranial arteries and extracranial carotid and vertebral arteries were found on MR angiography (fig. 2a-d). Transesophageal echocardiography and 24-hour Holter monitoring showed no abnormalities.

The patient was started on intravenous heparin $(21,600 \mathrm{U} /$ day) to prevent further thromboembolic complications; however,

\begin{tabular}{ll}
\hline KARGER & @ 2007 S. Karger AG, Basel \\
Fax +41 61 306 1234 $34-3022 / 08 / 0592-0076 \$ 24.50 / 0$ \\
$\begin{array}{l}\text { E-Mail karger@karger.ch } \\
\text { www.karger.com }\end{array}$ & $\begin{array}{l}\text { Accessible online at: } \\
\text { www.karger.com/ene }\end{array}$
\end{tabular}

Kyung-Yul Lee, MD, PhD

Department of Neurology, Yongdong Severance Hospital

Yonsei University College of Medicine

146-92 Dogok-dong, Kangnam-ku, Seoul 135-720 (Korea)

Tel. +82 22019 3325, Fax +82 23462 5904, E-Mail kylee@yumc.yonsei.ac.kr 
Fig. 1. Chest and abdominal CT scan. a Chest CT shows extended pleural effusion in the right chest. b Abdominal CT shows both ovaries enlarged with multiple cystic lesions and large amounts of ascites.
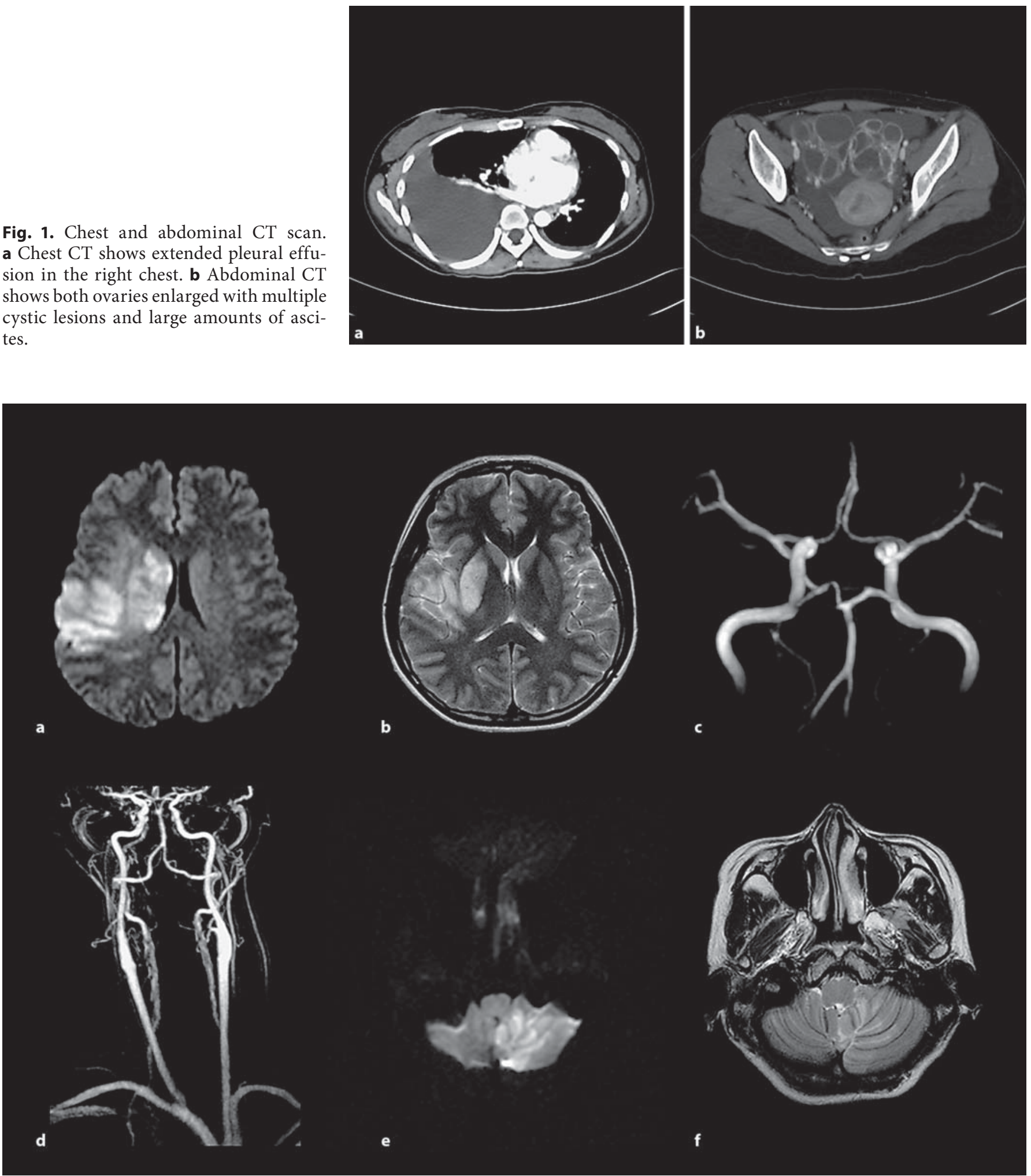

Fig. 2. Brain MRI and MR angiography. a, b Diffusion-weighted and $T_{2}$-weighted images show a high-signalintensity lesion in the territory of the right middle cerebral artery. $\mathbf{c}, \mathbf{d}$ MR angiography shows no significant intracranial and extracranial arterial stenosis or occlusion. e, f Follow-up diffusion-weighted and $\mathrm{T}_{2}$-weighted images show a newly developed, high-signal-intensity lesion in the left cerebellum. 
nystagmus and vomiting developed on day 3 after admission. A repeated brain MRI showed newly developed left cerebellar infarction (fig. 2e, f). On hospital day 12, serum hCG was found elevated to 3,463 $\mathrm{mIU} / \mathrm{ml}$ (4th week after conception normal range 1,000-20,000 $\mathrm{mIU} / \mathrm{ml}$ ), with subsequent abdominal ultrasonographic examination showing a triple pregnancy in the uterus. Surgical therapeutic abortion was performed on hospital day 21, and serum hCG, estrogen and progesterone levels returned to normal after the operation. The patient was placed on $100 \mathrm{mg} /$ day aspirin prophylaxis, and a 6-month follow-up examination revealed residual, mild left arm weakness and motor aphasia (NIHSS score 2).

\section{Discussion}

The mechanism of thromboembolism derived from OHSS is not fully understood. However, high serum estrogen concentration, hemoconcentration, reduced circulating blood volume by exhaustion of intravascular volume, and reduced venous return secondary to ovarian enlargement and ascites are possible pathomechanisms $[2,6,7]$. Furthermore, thromboembolism in OHSS can be associated with other hypercoagulable states, such as antiphospholipid antibody syndrome, antithrombin III deficiency and activated protein $\mathrm{C}$ resistance $[6,8,9]$.

Cerebral infarction rarely occurs as a complication of OHSS. The occurrence of progressive, multi-territorial infarctions, without atherosclerotic lesions in cerebral arteries visible on MRA, and the absence of a cardioembolic source suggest that systemic conditions conducive to a hypercoagulable state may be responsible for cerebral infarction in this case. We speculate that sustained high levels of hCG due to triple pregnancy, combined with a prior history of polycystic ovaries, may have led to severe OHSS and subsequent cerebral infarction, despite anticoagulation treatment. In addition, hyperactivation of the hemostatic system likely played a role in the development of thromboembolism. During pregnancy, and particularly in OHSS, markers of the hemostatic system, such as protein $\mathrm{C}$, protein $\mathrm{S}$, antithrombin III, tissue factor and D-dimer, are altered $[1,10-$ 12]. Decreased levels of protein $S$ and antithrombin III were observed at admission but normalized on the follow-up examination in this case. Therefore, we speculate that alterations of hemostatic factor may also contribute to the development of cerebral infarction. OHSS occurs more frequently and severely when combined with polycystic ovary syndrome $[2,3]$. Although the exact mechanism of this phenomenon is not clearly defined, it may be related to the exaggerated response to gonadotropin in polycystic ovary syndrome.

In conclusion, this case involved the severe complication of progressive, multiple cerebral infarctions in combination with OHSS and polycystic ovary syndrome. More stringent assisted-reproduction policies are necessary for preventing OHSS in a patient who also has polycystic ovary syndrome [13].

\section{References}

1 Delvigne A, Rozenberg S: Review of clinical course and treatment of ovarian hyperstimulation syndrome (OHSS). Hum Reprod Update 2003;9:77-96.

2 Avecillas JF, Falcone T, Arroliga AC: Ovarian hyperstimulation syndrome. Crit Care Clin 2004;20:679-695.

3 Tummon I, Gavrilova-Jordan L, Allemand MC, Session D: Polycystic ovaries and ovarian hyperstimulation syndrome: a systematic review. Acta Obstet Gynecol Scand 2005: 84:611-616.

4 Elford K, Leader A, Wee R, Stys PK: Stroke in ovarian hyperstimulation syndrome in early pregnancy treated with intra-arterial rt-PA. Neurology 2002;59:1270-1272.
5 Yoshii F, Ooki N, Shinohara Y, Uehara K, Mochimaru F: Multiple cerebral infarctions associated with ovarian hyperstimulation syndrome. Neurology 1999;53:225-227.

6 Stewart JA, Hamilton PJ, Murdoch AP: Thromboembolic disease associated with ovarian stimulation and assisted conception techniques. Hum Reprod 1997;12:21672173.

7 El Sadek MM, Amer MK, Fahmy M: Acute cerebrovascular accidents with severe ovarian hyperstimulation syndrome. Hum Reprod 1998;13:1793-1795.

8 Koo EJ, Rha JH, Lee BI, Kim MO, Ha CK: A case of cerebral infarct in combined antiphospholipid antibody and ovarian hyperstimulation syndrome. J Korean Med Sci 2002;17:574-576

9 Dulitzky M, Cohen SB, Inbal A, Seidman DS, Soriano D, Lidor A, Mashiach S, Rabinovici $\mathrm{J}$ : Increased prevalence of thrombophilia among women with severe ovarian hyperstimulation syndrome. Fertil Steril 2002;77: 463-467.

10 Rogolino A, Coccia ME, Fedi S, Gori AM, Cellai AP, Scarselli GF, Prisco D, Abbate R: Hypercoagulability, high tissue factor and low tissue factor pathway inhibitor levels in severe ovarian hyperstimulation syndrome: possible association with clinical outcome. Blood Coagul Fibrinolysis 2003;14:277-282.

11 Kodama H, Takeda S, Fukuda J, Miya H, Shimizu Y, Murata M, Tanaka T: Activation of plasma kinin system correlates with severe coagulation disorders in patients with ovarian hyperstimulation syndrome. Hum Reprod 1997;12:891-895.

12 Biron C, Galtier-Dereure F, Rabesandratana H, Bernard I, Aguilar-Martinez P, Schved JF, Hedon B: Hemostasis parameters during ovarian stimulation for in vitro fertilization: result of a prospective study. Fertil Steril 1997;67:104-109.

13 Homburg R: Management of infertility and prevention of ovarian hyperstimulation in women with polycystic ovary syndrome. Best Pract Res Clin Obstet Gynaecol 2004; 18:773-788. 